\title{
DISCURSO JORNALÍSTICO LEGITI- MADOR DA IDEOLOGIA NACIONAL DESENVOLVIMENTISTA DOS ANOS 70 EM SÃO BORJA
}

\author{
MARA REGINA RODRIGUES RIBEIRO \\ UNIVERSIDADE FEDERAL DO PAMPA \\ RIO GRANDE DO SUL, BRASIL \\ MARARIBEIRORODRIGUES@HOTMAIL.COM
}

HTTP://DX.DOI.ORG/10.5902/2316882X22593 
Resumo: este estudo se ocupa da produção jornalística impressa do jornal a Folha de São Borja, no período de 1969-1974, no Brasil. Apresenta-se uma análise sócia histórica, de onde se infere que há uma proximidade simbólica, atravessada pela exaltação das figuras públicas (políticos) e das temáticas nacionais. Esse estabelecimento retórico dialoga diretamente com a propaganda política governamental.

Palavras-chave: jornalismo; governo militar; ideologia.

\section{DISCURSO PERIODÍSTICO LEGITIMADOR DE LA IDEOLOGÍA NACIO- NAL DESARROLLISTA EN LOS AÑOS 70 EN SÃO BORJA}

Resumen: este estudio se ocupa de la producción periodística impresa del periódico la Folha de São Borja, en el periodo de 1969-1974, en Brasil. Presentase un análisis socia histórica, lo que se infiere es una asociación directa con las discusiones nacionales del periodo, donde se construye una proximidad simbólica, atravesada por la exaltación de las figuras públicas (políticos) y temáticas nacionales. Este establecimiento retórico dialoga directamente con la propaganda política gubernamental.

Palabras clave: periodismo; gobierno militar; ideología.

\section{LEGITIMATING JOURNALISTIC DISCOURSE OF NATIONAL DEVELO- PMENT IDEOLOGY OF THE TOS IN SÃO BORJA}

Abstract: This study occupies itself of the journalistic production of Folha de São Borja newspaper, period 1969-1974, in Brazil. It has presented a social-historical analysis, what infers is a direct association with the national discussions of the period, where builds a symbolic vicinity, crossed by the exaltation of the public figures (political) and thematic national. This rhetorical establishment has a conversation directly with the governmental political propaganda.

Keywords: journalism; military government; ideology. 


\section{INTRODUÇÃO}

O contexto sócio histórico do período do regime militar no Brasil produziu, de acordo com a Comissão dos direitos humanos da Câmara Federal, entre 1964 e 1979, cerca de 288 mortos e desaparecidos no Brasil; e 224 casos conforme dados da Comissão de mortos e desaparecido do Ministério da Justiça. Destaca-se que os 20 anos de governo não podem ser considerados homogêneos na condução da política econômica e social. Há diferenças relacionadas às linhas de pensamentos no interior das forças armadas brasileiras que determinou fases da repressão política, em que o autoritarismo governamental é fortalecido ou amenizado dentro do mesmo ciclo. Para Collier (1982), esses regimes se caracterizam por controlarem diferentes esferas da sociedade. Além disso, eles tendem a restringir a liberdade de expressão, principalmente, dos meios de comunicação social. No Brasil, por exemplo, a circulação da informação teve que se adaptar às recomendações das autoridades e eram comuns edições de atos institucionais ( $\mathrm{Al}$ ) e expedição de ordens através de ofícios, telegramas e ligações telefônicas.

No caso específico deste artigo se articulou como objeto de investigação o discurso jornalístico em que se analisa a ideologia e as relações de poder que se expressão no contexto autoritário. A pesquisa delineia a relação que se estabeleceu entre o interesse público nacional e as questões locais na cobertura jornalística impressa frente o ideário nacional desenvolvimentista implementado no Brasil na década de 60 e 70. Permitindo analisar as estratégias de legitimação do poder constituído, bem como identificar as justificações que os agentes sociais usam para preservar o poder e as relações de poder. O ponto principal do trabalho é o jornal FoIha de São Borja, desde seu surgimento na década de 1970 até 1973, período referente ao governo de Emilio Garrastazu Médici, terceiro presidente do regime militar no Brasil, cujo mandato foi em 30 de outubro de 1969, até 15 de março de 1974 .

O exame teve duas etapas, uma quantitativa e uma qualitativa. Na primeira foi realizada uma análise geral de todas as primeiras páginas, em que se buscaram os temas mais recorrentes e se estavam relacionadas ao âmbito local ou nacional.

Para essa coleta se definiu como tema as seguintes categorias: (1): Política, em que classificou as notícias ou títulos relativos às ações do agen-

Rev.Cad.Comun. Santa Maria, v.21, n.2, art 2, p. 35 de 51, maio/ago.2017 
te político - visitas e pronunciamentos - política de estado, política social como, por exemplo, a aplicação do censo nacional, a ampliação dos serviços do Instituto Nacional de Seguridade Social, evocações de uma personalidade política que já falecida, a realização de uma operação por parte do exército nacional; polícia - crimes e acidentes -, economia, internacional, esportes, saúde, educação, social - atividades sociais do clube, distinções, visitas - que não sejam de políticos, concurso de beleza, atividades culturais; fait divers e outros - temas correspondentes a inaugurações de casas comerciais, aposentadorias, questões do próprio jornal - compra de novos equipamentos, aniversário, celebrações religiosas ou chegada de religiosos, embelezamento da cidade. Assim se classificou porque os mesmo estão relacionados às editarias tradicionais que constituem os jornais em geral. Como âmbito distinguiu-se: (2) Local - apenas de São Borja, regional - São Borja e outras cidades do Estado - nacional - Brasil - e internacional - Brasil e outros países ou países estrangeiros exclusivamente.

Já na etapa qualitativa da análise, que se constituiu da observação mais detalhada das capas dos anos de 1970 a 1973, definiu-se uma amostra mais reduzida, a partir do seguinte critério: elegeu-se a capa que trazia o tema que mais se destacou nas tabelas sinópticas anuais. Por exemplo, em março de 1970 o conteúdo de destaque foi economia, então das cinco edições do mês, a do dia 24 era a que mais trazia questões de economia. Por este método selecionou-se quarenta e quatro (44) capas. Desse conjunto obtiveram-se os exemplos que ilustram a análise sócio histórica apresentada neste artigo.

O discurso jornalístico apresenta-se como uma construção social da realidade e é, conforme Thompson (1995), umas formas simbólicas, que correspondem a fenômenos culturais que podem ser ações, gestos, manifestações verbais, programas de televisão, obras de arte, filmes, músicas, jornais, revistas. Estas são carregadas de sentidos e significações que permitem que a ideologia se materialize. Esta, ainda, não é neutra. Segundo Silva (1998), a mesma existe quando se mobilizam ideias visando o estabelecimento e/ou a manutenção de relações de poder. É nessa perspectiva que se toma a ideologia, ressaltando que as formas simbólicas são ideológicas, quando e somente quando servem para estabelecer e sustentar relações sistematicamente assimétricas de poder e, assim, contribuem para reproduzir a ordem social que favorece indivíduos e grupos dominantes.

Quando se relaciona ao autoritarismo, a ideologia se refere a um siste-

Rev.Cad.Comun. Santa Maria, v.21, n.2, art 2, p. 36 de 51, maio/ago.2017 
ma simbólico que é funcional à legitimação de uma estrutura de dominação estatal, tecnocrata e desmobilizadora. Porque a especificidade dos fenômenos ideológicos decorre da funcionalidade de determinadas formas simbólicas em relação à manutenção ou ao estabelecimento de alguma estrutura de dominação.

Segundo Thompson (1995), ideologia é sentido a serviço do poder e estudá-la é compreender e explicar as maneiras pelas quais as produções culturais são usadas para a implantação e para a manutenção de relações de dominação. $O$ autor propõe uma concepção crítica da ideologia, vista como produto da vida social, das ações e interações entre os membros da sociedade e das mudanças simbólicas que ocorrem entre eles. Para Thompson (1995) o fenômeno da ideologia ganha um novo sentido e complexidade quando passa a ser visto como parte da circulação das formas simbólicas, viabilizadas pela mediação da cultura moderna.

\section{CONTEXTO DO GOVERNO DE MÉDICI}

Neste item a análise serve para contextualizar o jornalismo que se fiz na cidade através da produção jornalística no âmbito local, identificando as relações entre o discurso do jornal da Folha de São Borja e do governo.

Thompson (2009) indica que as formas simbólicas são produzidas por pessoas respondendo a contextos e situações que são típicas de um período. A produção da Folha de São Borja celebrou-se dentro de condições sociais históricas peculiares. Configurando-se como um dos vários exemplos de empresa jornalística local no Brasil, que ao longo do século XX cresceram em quantidade e qualidade, impulsionadas por distintas inciativas, muitas vezes privadas, motivadas por fatores, geralmente, político-partidários, na cultura do próprio profissional ou da sociedade onde se estabelece.

Quando o jornal surge em 1970, Emilio Garrastazu Médici tinha assumido como presidente de Brasil. No entanto, em seu governo continuam as características de regime militar que havia sido implementado nos anos 60. Mais especificamente deu-se continuidade ao modelo econômico implantado em Brasil desde a chegada dos militares ao poder: uma política que visa o crescimento econômico, tendo como principal idealizador o ministro da fazenda Antonio Delfim Netto, que atuava desde o governo Costa e Silva (1967/1969).

Rev.Cad.Comun. Santa Maria, v.21, n.2, art 2, p. 37 de 51, maio/ago.2017 
O crescimento econômico nos primeiros quatro anos do ciclo militar não foi significativo, caracterizando uma fase de pouco desenvolvimento, decorrente da política gradualista de combate a inflação adotada o governo Castelo Branco. No período entre 1968 e 1973 que chega a níveis expressivos, registrando taxa anual média de $11,2 \%$. Outros indicadores confirmavam o bom desempenho da economia, entre eles o da inflação em declino com taxa média anual menor que 20\%. (Brum, 2010)

Destaca-se, no entanto, que o momento próspero vivido pela economia brasileira entre 1969 e 1973 não se deu por milagre, apesar do apelido que se deu ao período. Isto aconteceu porque se seguiu a trajetória delineada nos programas econômicos dos primeiros generais presidentes, e se sustentou basicamente no endurecimento das relações de trabalho cobrindo o ajuste salarial e o controle sindical, e uma abertura, propiciada pelo Estado, para a entrada em massa do capital estrangeiro através empréstimos e investimentos.

Outra característica do modelo econômico nos anos 60 e 70 foi a inflação, um fenômeno complexo, cuja estabilidade da moeda depende principalmente da solidez da economia, da confiança da sociedade e de seu país, da cultura econômico financeira da população, da capacidade e da eficiência das autoridades no gerenciamento das políticas macroeconômica, do comportamento dos agentes econômicos e do grau maior ou menor de normalidade das relações econômico financeiras internacional. Além disso, quando as taxas inflacionárias são elevadas se fazem elemento perturbador das atividades econômicas e das políticas de preços e salários.

Durante alguns anos conseguiu-se conciliar um alto crescimento econômico com taxas inflacionárias declinantes, principalmente pela conjuntura mundial favorável, a elevada entrada de capital externo e à contração salarial da classe trabalhadora. Isso aconteceu entre os anos de 1968 e 1973.

O modelo econômico apresentava dois conjuntos de características básicas, segundo Brum (2010): periférico-sócio-dependente (plano externo) e elitista-concentrador e excludente (plano interno). O palco do capitalismo mundial há três atores com papéis distintos: os países centrais, altamente industrializados e ligados os grandes centros econômicos; as corporações multinacionais, com sede nos países centrais, mas cuja ação se entende por todos os continentes; e os países periféricos, compreendi-

Rev.Cad.Comun. Santa Maria, v.21, n.2, art 2, p. 38 de 51, maio/ago.2017 
dos como em subdesenvolvimento ou em desenvolvimento.

A característica de associado é porque o país aceitava e estimulava a entrada e a atuação de empresas estrangeiras, apoiava a associação das nacionais com as estrangeiras e procurava estreitar os vínculos com o centro do capitalismo internacional, expõe Brum (2010). A associação ao capital estrangeiro traz algumas facilidades e também problemas. Entre as facilidades destacam-se a possibilidade de uso imediato da tecnologia oriunda do exterior, a entrada do capital do exterior, acesso a créditos dos bancos multinacionais, exportação e geração de empregos. Quanto aos problemas tem-se: a transferência dos centros de decisão sobre importantes setores da economia para o exterior, onde estavam as matrizes e os laboratórios das empresas; a inadequação de muitas tecnologias importadas para o nível de desenvolvimento que o país apresentava. Os aspectos elitistas-concentradores e excludentes, perspectiva mais negativa da política econômica, foram de natureza social, segundo Brum (2010) enquanto valorizavam-se os empregos, acentuou-se a contradição entre o crescimento econômico e o avanço industrial, como também aumentou a degradação ambiental.

Brum (2010) afirma que o regime militar não teve sensibilidade para reorientar a estrutura industrial de Brasil, isso porque os governos militares desconsideram a oportunidade histórica de repensar os hábitos de consumo recentemente introduzidos na sociedade e imprimir mudanças profundas na industrialização brasileira. Com isso, o modelo de desenvolvimento vigente no país ao longo do ciclo militar manteve a característica centralizadora, porque beneficiou a grande empresa em detrimento da média e da pequena, estimulou a fusão de empresas, favoreceu a concentração da propriedade de terra, possibilitou a expansão econômica nos estados e nas regióes mais ricas, privilegiou o interesse do capital em detrimento dos ganhos do trabalho.

Assim, se pode constatar que transformações estruturais na economia e mudanças na divisão do trabalho já ocorriam e estavam a adquirir mais velocidade nos últimos anos. Ocorreram distinções sociais no trabalho, como também, o crescimento de atividades secundárias e terciárias, substituição da atividade de artesanato pela industrial e tive a criação de novos tipos de serviço. No entanto, a distorção na distribuição de renda faz-se mais transparente. Os salários têm peso importante neste processo, não obstante o agravamento do perfil da distribuição de renda decorreu da 
política perversa implementada pelo governo, conforme Brum (2010), que fixava os índices de reajustes sempre inferiores às taxas de inflação.

A realidade econômica influência a vida dos grupos familiares, coloca-os, muitas vezes, em situação de pobreza e de miséria. Delas decorrem a carência alimentar, as dificuldades na escolarização, os obstáculos à ascensão social e as barreiras e os limites na participação política, as deficiências na saúde, moradia, mortalidade infantil. Com isso, o processo de marginalização no Brasil acabou por agravar velhos problemas sociais já existentes. Médici deu continuidade ao quadro instaurado desde 1964 e que, naquele momento, não demonstrava sinais de mudança na austeridade governamental.

Para Romancini \& Lago (2007, p. 120-21) ao lado de mecanismos estritamente autoritários e de força direta, teve uma pressão econômica, particularmente importante num momento em que o Estado começou a assumir um papel mais central ainda nas atividades econômicas. Neste aspecto, há um favorecimento aos grupos de comunicação ligados à televisão principalmente à Rede Globo, devido à realização de uma política de integração nacional, que envolve grande aporte de recursos financeiros e tecnológicos por parte do Estado, considerando o caráter estratégico com que era visto este meio.

Resende (2008) avalia que os sucessivos governos no Brasil buscaram o controle dos meios e consequentemente da opinião pública y que o faziam mediante o controle da informação, exercido através da censura empresarial, econômica e política. O que sempre ocorreu, afirma o autor, foi que o poder não quer ouvir verdades - ou pelo menos não deseja que elas sejam divulgadas a população. Com isso, evitam a manifestação da cidadania, que se dá, em primeiro lugar, mediante o conhecimento da realidade do país e do que nele acontece. A informação, neste caso, é imprescindível para que o espaço de manifestação dos cidadãos exista.

Nesse contexto sócio histórico em que a Folha de São Borja estava inserida e desenvolveu uma produção que não foi suficiente para dar conta das contradições e pluralidade do momento, porém refletiu uma realidade que estava muito alinhada ao discurso do poder vigente e de sua ideologia. Sobre censura, por exemplo, a naturalizou e minimizou suas consequências.

Fico (2004) indica que não teve uma única censura durante o regime militar, mas sim duas: à imprensa e ao entretenimento público. A primeira

Rev.Cad.Comun. Santa Maria, v.21, n.2, art 2, p. 40 de 51, maio/ago.2017 
era revolucionária, ou seja, não regulamentada por normas ostensivas. Focalizada, sobretudo em temas políticos. A segunda era antiga e legalizada, existia desde 1945 e era algo familiar para os produtores de teatro e de cinema, os músicos e outros artistas. Era praticada por funcionários especialistas (os censores) e por eles defendida com orgulho. Amparava-se na longa e ainda viva tradição de defesa da moral e dos bons costumes, de diversos setores da sociedade brasileira.

Esse mesmo autor realça que é possível apontar problemas e contradições entre ambas censuras. A principal foi a penetração da dimensão estritamente política na censura de costumes - justamente em função da vitória da linha dura, corrente de pensamento dentro do exército, caracterizada pelo Al-5. Isto transpareceu a impressão de unicidade das censuras. Na imprensa, a censura acompanhou o incremento da repressão, em especial quando aconteceram revogações de mandatos parlamentares, suspensões de direitos políticos, prisões, torturas e assassinatos políticos, e teve seu auge entre finais dos anos 60 e início dos anos 70. A censura do entretenimento público, agrupou os temas da moral e dos bons costumes, por sua vez, teve auge no final dos anos 70, já durante a abertura política. Segundo Abreu (2005, p. 53), o período de 1974 a 1989 é da transição do regime autoritário à democracia em Brasil. Em 1974, quando o general Ernesto Geiser assumiu a presidência da República, começou a ser posto em prática um projeto o processo de abertura política.

Fico (2004, p.7) explica que na censura do entretenimento público, por exemplo, "sobrelevam, evidentemente, os conflitos entre setores mais conservadores da sociedade de então e questões referidas às mudanças comportamentais (como o movimento hippie, a liberalização das práticas sexuais e as manifestações artístico-culturais das "vanguardas")".

No jornal Folha de São Borja a noticia presentada a seguir explicita esta perspectiva moral, porque destaca a linguagem utilizada pelo compositor, considerada vulgar: 


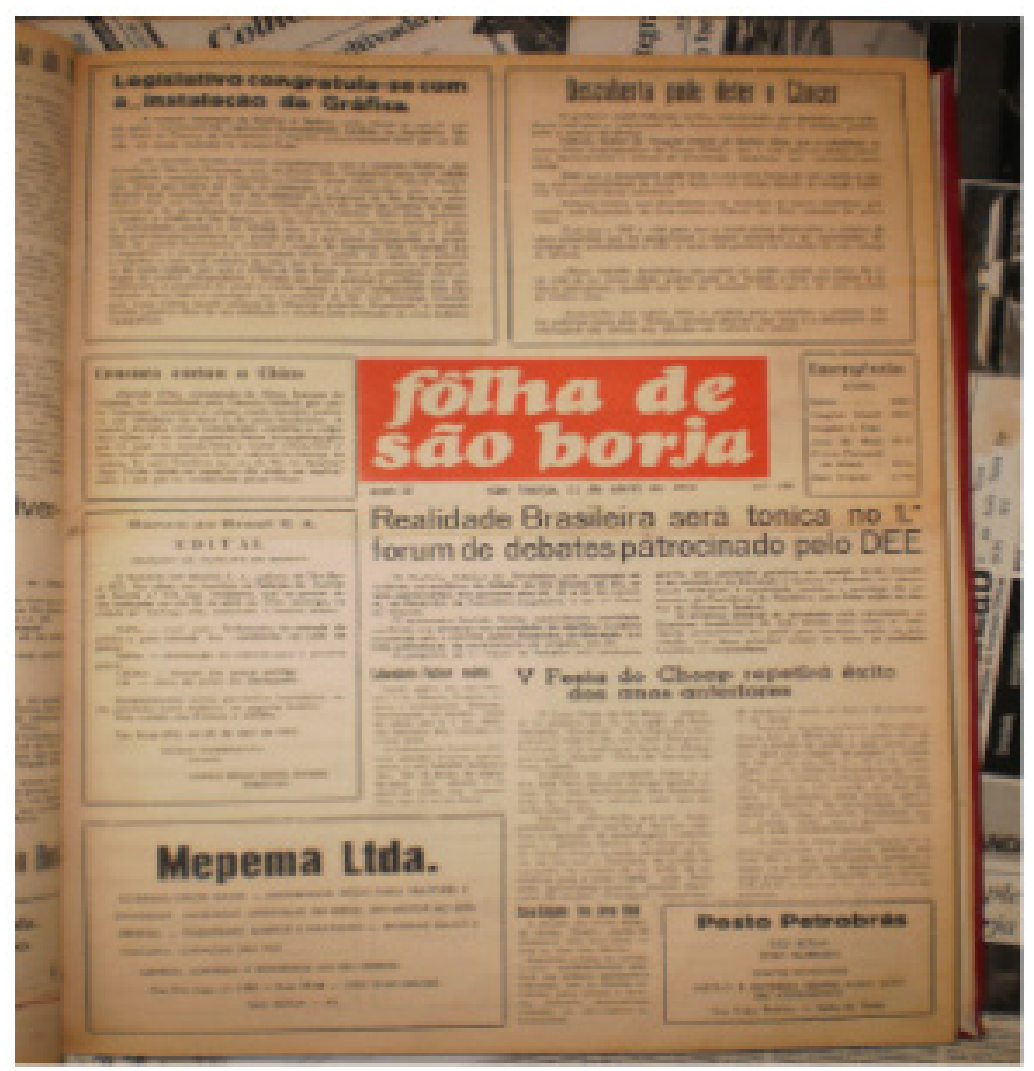

Figura 01 - Censura dos divertimentos públicos - 11/04/1972

Fonte: arquivo Folha de São Borja

Chico Buarque de Holanda, o músico e compositor brasileiro a quem faz referência a notícia, teve sua carreira marcada pelo período do governo militar, em especial devido à perseguição por parte dos censores que proibiram a execução de grande parte de suas canções. A música vetada era uma composição para o filme "Quando o carnaval chegar", do cineasta Cacá Diegues. Nos versos proibidos foram trocadas as palavras consideradas problemáticas. Em "Na barriga da miséria, eu nasci brasileiro", mudou para "nasci batuqueiro"; e em "Jesus Cristo inda me paga, um dia inda me explica/Como é que pôs no mundo esta pouca titica, para "pobre coisica" (Informação disponível em: http://www.chicobuarque.com.br/letras/partido_72.htm).

Na censura ao material cultural ou à imprensa, segundo Mattos (2005), estava incorporada a ideia de contribuir para a consolidação de uma mentalidade de segurança nacional do discurso político do governo segundo o qual esta era indispensável para a defesa da democracia e a garantia do esforço coletivo rumo ao desenvolvimento.

No caso da produção da Folha de São Borja existe uma adaptação à conjuntura política da época e para isto utiliza de outros elementos agre- 
gadores como, por exemplo, o futebol que permitiu a exaltação ao Brasil, pela vitória na Copa do mundo de futebol. Por outro lado, também destacava a importância do município na economia nacional, como se este fosse protagonista e não coadjuvante. Essa estratégia aproxima o que está distante - o futebol - ao que está próximo - a produção agrícola que se expande no município em uma lógica que responde ao interesse local/nacional, indicando que a planificação para o Brasil também estava na cidade. Assim como o orgulho de ser brasileiro, que além de ser trabalhador, era naquele momento, vitorioso pela conquista do mundial.

A adesão popular ao projeto governamental era considerada condição básica para a consecução dos objetivos nacionais. No seu pronunciamento como candidato à Presidência, Médici assegurou não acreditava em plano de governo que não correspondesse a uma ação nacional. Ele afirmou que, na marcha para o desenvolvimento, o povo deveria ser o protagonista e não somente espectador (MATOS, 2008 p.175).

Brum (2010, p. 324) explica que a capitalização do sucesso desportivo em México, juntamente com a divulgação de um bom desempenho na econômica tinha por objetivo transformar o país num lugar mais atraente aos investimentos estrangeiros, o que realçava a política econômica do governo Médici, comandada por seu ministro Delfim Neto.

Segundo Matos (2004, p. 173),

[...] o clima de ufanismo disseminado no período Médici foi alimentado por dois fatores básicos: a explicação da vitória do Brasil na Copa do Mundo [de 1970] como consequência do apoio do governo à seleção 'canarinho', aproveitando a paixão do brasileiro pelo futebol, e o uso da propaganda para a construção da imagem de país em acelerado crescimento econômico.

Os elementos de composição jornalística - título, texto e publicidade - são instâncias para explicar como o discurso do jornal era construído. Tinha um predomínio de notícias e titulares locais nas páginas - como se esteve demonstrado no quadro sinóptico capas. 
CADERNOS DE COMUNICAÇÃO

UNIVERSIDADE FEDERAL DE SANTA MARIA

\begin{tabular}{|c|c|c|c|c|c|}
\hline $\begin{array}{c}\text { Ano } \\
\text { Edições }\end{array}$ & Manchetes & Âmbito & Noticias & Âmbito & Anúncios \\
\hline \begin{tabular}{c}
\multicolumn{2}{c}{1970} \\
Total 46
\end{tabular} & $\begin{array}{c}\text { Politica } \\
16\end{array}$ & $\begin{array}{l}\text { Local } \\
25\end{array}$ & $\begin{array}{c}\text { Economia } \\
26\end{array}$ & $\begin{array}{c}\text { Local } \\
89\end{array}$ & $\begin{array}{c}\text { Nacional } \\
5\end{array}$ \\
\hline $\begin{array}{l}1971 \\
\text { Total }\end{array}$ & $\begin{array}{l}\text { Politica } \\
13\end{array}$ & $\begin{array}{l}\text { Local } \\
31\end{array}$ & $\begin{array}{l}\text { Social } \\
36\end{array}$ & $\begin{array}{c}\text { Local } \\
169\end{array}$ & $\begin{array}{c}\text { Local } \\
9\end{array}$ \\
\hline $\begin{array}{c}1972 \\
\text { Total }\end{array}$ & $\begin{array}{l}\text { Politica } \\
\quad 21\end{array}$ & $\begin{array}{c}\text { Local } \\
37\end{array}$ & $\begin{array}{c}\text { Outro } \\
35\end{array}$ & $\begin{array}{c}\text { Local } \\
158\end{array}$ & $\begin{array}{c}\text { Local } \\
14\end{array}$ \\
\hline \begin{tabular}{c}
\multicolumn{2}{c}{1973} \\
Total
\end{tabular} & $\begin{array}{c}\text { Social } \\
6\end{array}$ & Local 18 & $\begin{array}{c}\text { Politica } \\
11\end{array}$ & $\begin{array}{c}\text { Local } \\
77\end{array}$ & $\begin{array}{c}\text { Nacional } \\
2\end{array}$ \\
\hline
\end{tabular}

Quadro 01: quadro síntese dos anos analisados

Porém, há uma ênfase nacional, ou seja, repercutem-se ações locais que são realizadas ou são vivenciadas localmente em função de uma ação desenvolvida. Abaixo se reproduz mais um o texto que corrobora essa ideia. O âmbito é local, porque a rodovia 285 circunda as cidades da região, ainda a expansão econômica a que o texto face refere relacionasse com o país.

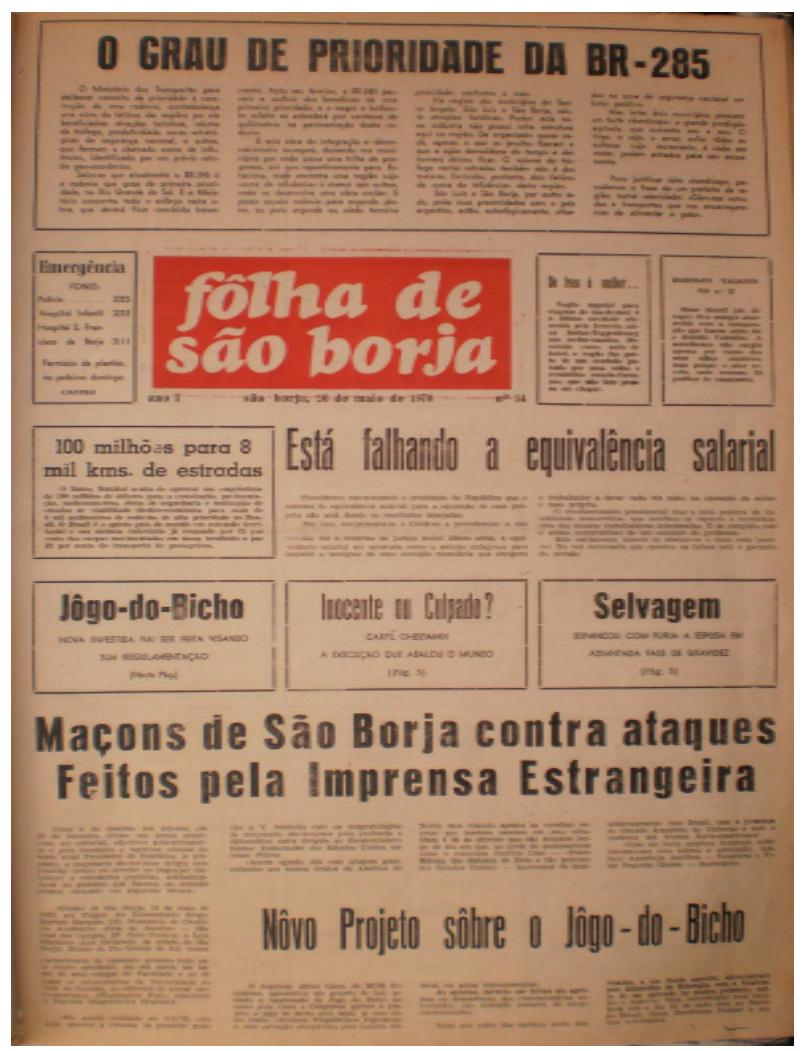

Figura 02 - Prioridade local enfatizada pelo interesse nacional - 26/05/1970 Fonte: arquivo Folha de São Borja

Rev.Cad.Comun. Santa Maria, v.21, n.2, art 2, p. 44 de 51, maio/ago.2017 
Nas páginas do jornal há a repercussão das gestões da esfera macro da sociedade, ou seja, a notícia federativa que chega à cidade do interior. Implementando assim uma proximidade que a primeira vista é temática, mas que na realidade é simbólica. A proximidade que se estabelece é social, como indica Fontcuberta (2011), há uma vinculação do reconhecimento.

Este aspecto pode ser assinalado quando a informação jornalística está relacionada a um acontecimento local, ainda este ocorre porque pertence a um fato mais amplo como, por exemplo, as comemorações cívicas em honra à independência de Brasil ou as homenagens aos símbolos nacionais como a bandeira. A seguir, apresentam-se textos referentes às atividades de sete de setembro, que tiveram como local a praça XV, principal espaço público de São Borja. O destaca é para a parada cívico-militar do ânus de 1972. Evento importante porque integrava a programação das comemorações dos 150 anos da independência do Brasil.

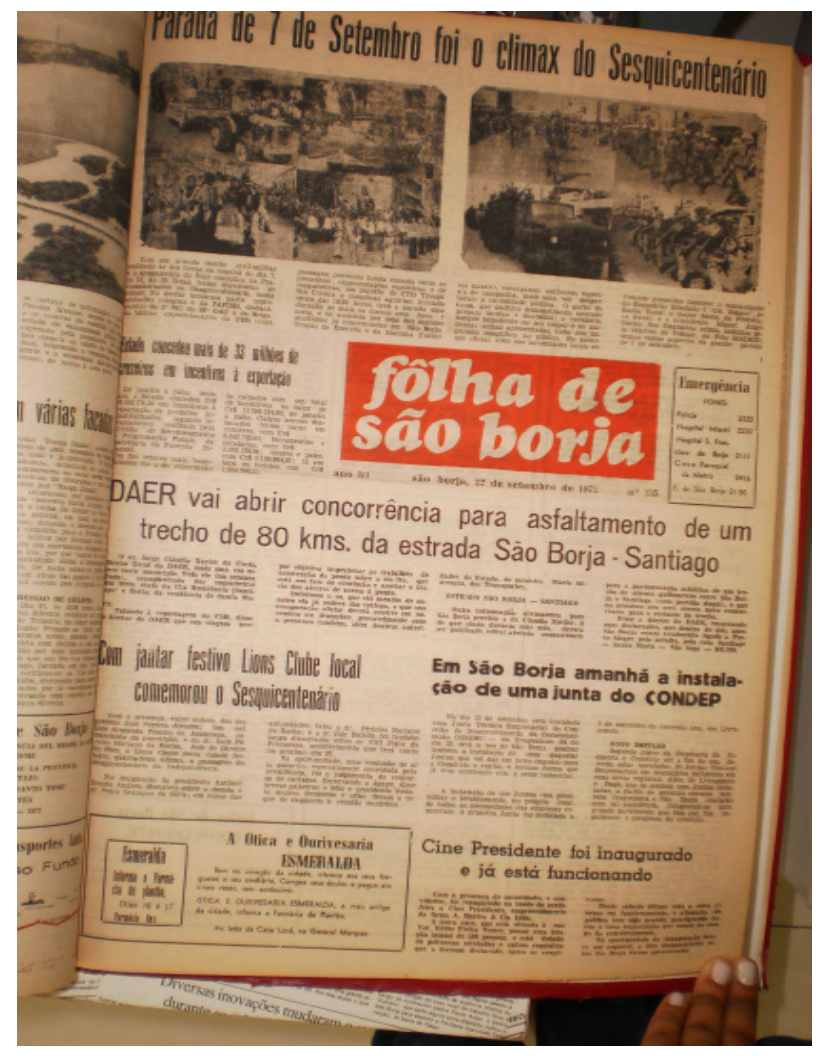

Figura 03 - Desfile de 7 de setembro - 12/09/1972

Fonte: arquivo Folha de São Borja

O texto que acompanhava a manchete "Parada de 7 de Setembro foi o clímax do Sesquicentenário" (FSB, 1972) fazia refere a emoção que o bilhete na avenida dos expedicionário da FEB causaram a população presente e a curiosidade que as tropas do exército e da marinha suscitaram 
nas pessoas por seu uniforme, disciplina, técnica e armas apresentadas no desfile. Além disso, destacava que e autoridades estrangeiras, no caso da argentina, prestigiaram o evento, o promove um sentimento de cooperação internacional e reconhecimento da importância do evento. Com esses apontamentos se delineia o ambiente no qual se desenvolveu o fato. Conforme Fontcuberta (1998, p. 120), "todo ellos son elementos que contribuye a explicar con más profundidad los hecho".

A proximidade nacional/local ocorre não só com os temas relacionados a Brasil como nação, mas também com outros assuntos que permitem o reforço da unidade que o governo nacional procurava colocar em prática. Na análise quantitativa das capas dos jornais, por exemplo, há uma tendência nas manchetes pelo tema política, como se destaca abaixo:

\begin{tabular}{|c|c|c|}
\hline Ano & Total de ediç̃os & Titulares \\
\hline 1970 & 46 & Política 16 \\
\hline 1971 & 49 & Politica 13 \\
\hline 1972 & 51 & Politica 21 \\
\hline 1973 & 46 & Social 6 \\
\hline
\end{tabular}

Quadro 02: quadro sinóptico dos anos analisados - tema das manchetes

Porém, a questão política a que o jornal noticiava não era a partidária, visto que em o período estava em vigor o bipartidismo, que se implementou com a edição do Ato Institucional No 2 (Al-2) ainda em 1965, no governo de Castelo Branco. Em função da imposição a formação partidária foi artificialmente engendrada no Congresso nacional, o que determinou a coabitação, de baixo de um mesmo partido, políticos que em outra situação eram adversários. Para Fleischer (2004, p. 254) as regras para a formação dos novos partidos em este período eram relativamente simples, sendo necessário somente "arregimentar 120 deputados federais e 20 senadores. Em tese, poderiam ter sido organizados três partidos novos, mas na prática foi difícil até mesmo construir dois."

Por isto que no Brasil mal tinham dois partidos: a Aliança Renovadora nacional (Areia), de direita; e Movimento Democrático Brasileiro (MDB), de oposição. O bipartidismo foi um dos elementos que garantiu a criação de uma aparente normalidade e legalidade no país, importante para a ima-

Rev.Cad.Comun. Santa Maria, v.21, n.2, art 2, p. 46 de 51, maio/ago.2017 
gem do governo.

Fleischer (2004) explica que a Arena se formou relativamente fácil devido as adesões governamentais, Enquanto o MDB “teve dificuldade em juntar os 20 senadores e contou com uma pressão discreta do presidente Castelo Branco para convencer dois senadores filiar-se temporariamente ao MDB". (FLEISCHER, 2004, P. 254)

O jornal apresentavam as ações principalmente dos integrantes dá areia, que pela disputa eleitoral de 1966 tinha 67,5\% da câmara dos deputados, em contra $32,5 \%$ do outro partido político. Nos dois textos abaixo se evidencia a tendência. No primeiro se informa a formação de um novo diretório partidário, já o segundo, elenca algumas reivindicações apresentadas pelo prefeito da cidade ao futuro governador do estado do Rio Grande de o, que em comitiva visitava a região.

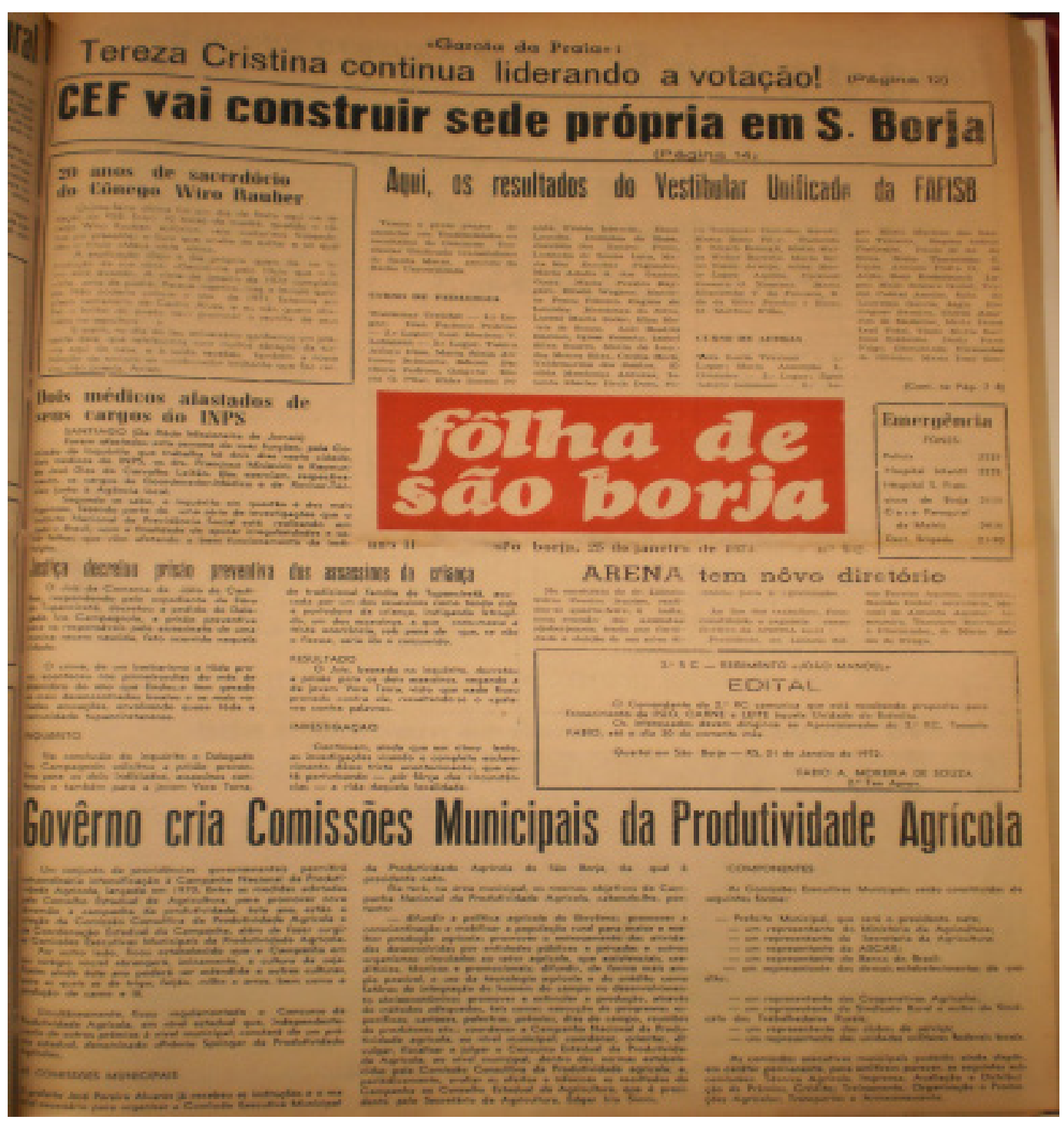

Figura 04 - Notícia a respeito da Arena - 25/01/1972

Fonte: arquivo Folha de São Borja

Rev.Cad.Comun. Santa Maria, v.21, n.2, art 2, p. 47 de 51, maio/ago.2017 
Neste contexto a política, não se caracterizou pela disputa pelos debates de ideias dada a centralizada de poder que o governo militar implantou. Essa diversidade pode ser comprovada na análise quantitativa que se realizou nas capas e que se explicita no quadro sinóptico a seguir:

\begin{tabular}{|c|c|c|}
\hline Ano & Total de edições & Noticias \\
\hline 1970 & 46 & Economia 26 \\
\hline 1971 & 49 & Social 36 \\
\hline 1972 & 51 & Outro 35 \\
\hline 1973 & 46 & Política 11 \\
\hline
\end{tabular}

Quadro 03: quadro sinóptico dos anos analisados - temática das notícias

Apesar da variedade se encontrou muitas matérias sobre as questões econômicas, isto porque essa área, no governo de Médici, apresentou uma expansão considerável, visto que o produto interno bruto (PIB) teve aumento e ocorreu a consolidação de uma nova classe média com alto poder aquisitivo. Nesse período o país estava baixo a influência do Milagre Brasileiro que "estendeu-se de 1969 a 1973, combinando o extraordinário crescimento econômico com taxas relativamente baixa de inflação. A inflação média anual não passou de 18\%”. (Bosi, 2002, p. 268), isto porque tinha disponibilidade de recursos financeiros para empréstimos externos e investimentos de capital estrangeiro. A política financeira do governo militar ditou o ritmo de um acelerado processo de industrialização, baseado então numa grande quantidade de capital estrangeiro.

Brum (2010) explica que essa política tinha como referencial o padrão de produção e consumo da sociedade norte-americana. No entanto, no Brasil para garantir a todos o acesso aos bens no padrão de uma economia forte, "buscou-se uma sintonia entre os interesses de expansão das grandes empresas" e se priorizou, sobre tudo o setor industrial, a atenção ao consumo da população de rendimentos mais altos, cerca de $20 \%$ dos brasileiros. (BRUM, 2010, p. 342) 


\section{CONSIDERAÇÕES FINAIS}

A partir da analise sócio histórica, da vinculação com os modos e estratégias do discurso ideológico, aponta-se que na Folha de São Borja, não há uma distinção entre a esfera local e nacional, porque para o jornal a cidade de São Borja tinha uma importância e uma proximidade com as autoridades e personagens nacional que a colocavam no centro das atenções, principalmente pela ênfase que se dá à questão econômica, identificando o município como capital da produção. Assim, pelo menos anuncia por seu discurso.

Também se ressalta que o jornal ao destacar a cidade, fez como se o semanário estivesse um alcance e uma circulação nacional. Assim, se explica que fatos locais tenham relação com o âmbito nacional, porque se considera São Borja como Brasil em escala menor e que reproduz também os atributos que naquele período eram destacados do país. As características podem ser sintetizadas por três adjetivos: força, modernidade e civismo. A primeira, herdada na tradição e história dos povos jesuítas, assim como o Brasil, que destaca um passado heróico, apropriado aos portugueses e bandeirantes. A segunda realça o desenvolvimento e a modernidade por médio da produção agrícola, que lhe confere apodo de capital da produção, e, esse desenvolvimento econômico a põe na dianteira, como que a guiar a cidade/Brasil no caminho do progresso. Os guias são homens públicos de valorosos, salvadores - que se empenham e se sacrificam por sua comunidade. $O$ último atributo está no civismo da comunidade que honra sua terra e a demonstra nas diversas oportunidades, principalmente nas manifestações públicas de homenagem a pátria brasileira ou ao estado do Rio Grande do Sul.

Essas propriedades configuram e afirmam um imaginário que reflete a busca pela legitimação através da universalização, em que "acordos institucionais que servem os interesses de alguns são apresentados como servindo aos interesses de todos..." (Thompson, 2009, p. 83). Além disso, é um discurso dissimulado em que se toma a parte pelo todo - a cidade e seu desempenho político, social e econômico como representativo do país.

Segundo Cerri (2002, p. 1) é o que se pode chamar de ideologias geográficas do regime militar, assim como seu nacionalismo em geral, pode ser compreendido também como ferramenta de ajustamento social, pois

Rev.Cad.Comun. Santa Maria, v.21, n.2, art 2, p. 49 de 51, maio/ago.2017 
reforça o sentimento de pertencer a uma nação que pode não ser necessariamente onde se tenha nascido ou se esteja naquele momento porque esse lugar "é, genericamente, o Brasil. [...] Sua compensação imaginária é pertencer a um Estado-nação [...]"

O universo discursivo do semanário se construiu e buscou legitimar-se a partir da utilização das técnicas e prática do próprio fazer jornalístico, que por seus aspectos institucionalizados legitima o discurso da empresa Folha de São Borja. Quando se organiza um jornal, se cria de certa forma uma expectativa, por aquilo que Mouilloud (2002) aponta como nome-de-jornal, uma produção impressa que guarda característica de forma e conteúdo que se transformaram e se instituíram ao longo do tempo.

\section{REFERÊNCIAS}

BRUM, A. Desenvolvimento econômico brasileiro. 24. ed. Petrópolis: Vozes, 2010.

CERRI, L. Ensino de História e Nação na Propaganda do Milagre Econômico. Revista Brasileira de História. vol.22 no.43. São Paulo, 2002

CODATO, A. História política recente no Brasil (1974-2002). disponível em: http:// www.ifcs.ufrj.br/ lemp/imagens/textos/Historia_politica_recente_no_Brasil.pdf. Acesso em $14 / 05 / 2012$

COIMBRA, C. Produção do Medo e da Insegurança. Disponível em: http://www.slab. uff.br/textos/texto64.pdf. Acesso em 20/02/2012.

COLLIER, D (org.). O Novo Autoritarismo na América Latina. Rio de Janeiro: Revista Eletrônica Boletim do Tempo, Ano 4, n¹9, 2009.

FONTCUBERTA, M. La Noticia - Pistas para percibir el mundo. Barcelona: Paidós, (2011).

GASPARI, E. A Ditadura Escancarada. Vol 2. Coleção As Ilusões Armadas, São Paulo: Companhia da Letras, 2001.

Rev.Cad.Comun. Santa Maria, v.21, n.2, art 2, p. 50 de 51, maio/ago.2017 
MATOS, H. Governo Médici: discurso oculto na comunicação institucional - o caso AERP in. História das relações públicas: fragmentos da memória de uma área [recurso eletrônico] / Cláudia Peixoto de Moura (Org.) -Porto Alegre : EDIPUCRS, 2008.

RESENDE, L. A censura contra a cidadania: o caso do Brasil. Acesso em 23/8/2008. Disponível em: http://www.bocc.ubi.pt/_listas/tematica.php?codtema=17.

ROMANCINI \& LAGO. História do Jornalismo no Brasil. Florianópolis: Insular, 2007.

SANTOS, R. Propaganda política do governo Médici. Disponível em: http://falandodeteologiaehistoria.blogspot.com.br/2012/01/propaganda-politica-do-governo-medici. html - acesso em 18-06-2012.

SILVA, R. A Ideologia do Estado Autoritário no Brasil. Chapecó: Argos, 1998.

THOMPSON, J. Ideologia e Cultura Moderna: teoria social crítica na era dos meios de comunicação de massa. Petrópolis: Vozes, 2009.

THOMPSON, J. A mídia e a modernidade: uma teoria social da mídia. 4 ed. Petrópolis: Vozes, 2002.

\section{Mara Regina Rodrigues Ribeiro}

Doutora em Ciências Sociais/Flacso/Argentina. Mestre em Ciências Sociais (Unisinos). Especialista em Pensamento Político Brasileiro (UFSM). Pesquisadora do Grupo de Pesquisa História da Mídia (Unipampa) e Docente no Curso de Jornalismo da Universidade Federal do Pampa - Unipampa. E-mail: mararibeirorodrigues@hotmail.com

RECEBIDO EM: 09/06/2016

ACEITO EM: 08/08/2016

Rev.Cad.Comun. Santa Maria, v.21, n.2, art 2, p. 51 de 51, maio/ago.2017 